\title{
The Effect of Home-Based Supportive-Educational Counseling on Primigravidas' Postpartum Stress
}

\author{
Ali Navidian ${ }^{1}$, Ameneh Safarzadeh Sarasiyabi², Maryam Koochakzai ${ }^{2 *}$
}

\begin{abstract}
Objectives: Planned interventions can facilitate the maternal role for primiparous women by reducing postpartum stress. The present study aims to determine the effect of home-based supportive-educational counseling on primigravidas' postpartum stress. Materials and Methods: In this quasi-experimental study, 100 primigravidas, who had routinely referred to health centers from May to June 2016 for postpartum care on the third to fifth day after delivery, were selected and randomly assigned into two intervention $(\mathrm{n}=50)$ and control $(\mathrm{n}=50)$ groups. The Hung Postpartum Stress Scale (HPSS) was used for data collection. The intervention group underwent three supportive-educational sessions at home and the control group underwent usual postpartum care and trainings. Postpartum stress in both groups was evaluated at the end of sixth week after delivery. The gathered data were analyzed using statistical tests including independent $t$ test, paired-sample $t$ test, chi-square, and analysis of covariance (ANCOVA).

Results: The mean score of postpartum stress as well as scores of three subscales of maternal role attainment, negative body changes and lack of social support after implementing home-based supportive-educational intervention in the intervention group were significantly lower than the control group $(P=0.0001)$.

Conclusion: Given that home-based supportive-educational intervention has a significant and positive effect on postpartum stress reduction; therefore, visiting at home and providing supportive-educational counseling are recommended for postpartum programs. Keywords: Education, Postnatal care, Postpartum period
\end{abstract}

\section{Introduction}

The postpartum period is one of the important transitional phases in women's life (1). Following serious changes of delivery and transition to parenthood, primigravidas undergo significant physical, social and psychological changes (2). With important physiological and psychological changes such as adapting to changes in the body, woman face maternal role and support of certain people (3). Therefore, mother needs to adapt to new life and newborn care (4). Most of them aren't ready to take care of themselves and their baby with plentiful needs (5). During this stage of adjustment, mother experiences psychosocial social imbalances that lead to severe stress (6). The true prevalence of postpartum stress among women is unknown, but studies show that $10 \%$ to $15 \%$ of women are affected by mental issues including depression, anxiety and stress after delivery (7). Webb et al showed that $69 \%$ of women have at least one physical complaint after childbirth (8). Based on the results, $25.71 \%$ to $32.38 \%$ of women have mild mental disorders during the first 6 weeks after delivery (9) and, in some studies; this figure has even reached up to $44.4 \%$ (10). In Iran, $47.5 \%$ of nulliparous women and $67.1 \%$ of multiparous are not in a good mental health status (11) and 32\% of women experience postpartum stress disorder after delivery (12). Overall, postpartum stress in Iranian women is higher than other countries and is inversely related to social protection (13). Many diseases and problems of women in this period are related to stress or their inability to cope with changes (14). Stress can be a component of any disease. Therefore, understanding the stressors and improving the capacity of the person to be compatible with them is very important (3).

Episiotomy and perineal pain, back pain, breast swelling and pain, incontinence, constipation, fatigue, sleep problems and breast problems are the most important physical stressors and the pressure to return to pre-pregnancy weight, sexual changes, concerns about the maternal role, problems regarding the infant (e.g., feeding, crying, care, bathing, unpredictable behaviors of the baby, sucking, neonatal jaundice, sleep disorders, flatulence, inadequate weight gain, eye infection and umbilical infection), relationships with partners and lack of social support are psychological stressors (15-17). Baby care, sexual relationships, self-care, family planning and mental health are women's concerns and educational needs in the postpartum period (18). Based on the analysis of various factors, Hung et al found that three factors of maternal role attainment, lack of social support and physical changes are important in the occurrence of postpartum stress (5).

Postpartum stresses are determinants of women's health and even threaten child-parent relationship and child 
development (19). Postpartum stress, especially in nulliparous women, is directly related to postpartum mental disorders such as anxiety and depression (9). Mother's emotional and psychological problems due to high stresses impair her relationship with the child, may affect the rate of mother-infant attachment and child's cognitive, emotional, social and behavioral development and have a negative effect on the health of mothers, children and other members of the family $(5,20)$. Maternal stress may be associated with complications such as lactation problems, child's excessive crying, child's irritability, sleeping neonates (21) that may have a negative impact on woman's health, her relationship with spouse and quality of her relations with neonate (22) and may lead to poor parenting practices including violence against children and have a negative effect on parental efficiency (23).

Although postpartum stress is directly associated with minor psychiatric disorders, but few studies have investigated the impact of interventions on reduction of stress after delivery and most studies have focused on postpartum depression in women at risk (24). However, studies show that women in the postpartum period do not get proper trainings about self-care and newborn care, breastfeeding and nutrition, resuming sexual activity, coping with physical problems, etc $(15,21)$.

Planned interventions can facilitate maternal role for primiparous women by reducing postpartum stress (9) and increase mother's self-efficiency in activities regarding child care (25). Studies show that oral trainings in postpartum unit of hospitals do not sufficiently increase women's awareness of problem solving (26). In recent years, the emphasis has been on the importance of using interventions for mental health management in the postpartum period instead of using the usual health care (27). One of the best midwifery interventions to increase women's awareness and reduce their stress is counseling and training (28).

Home visiting programs and maternal and child health examination in the postpartum period are very important. Effective interventions in this area increase and sustain women's physical and mental health, improve children's health and relationships with spouse, and increase compatibility. Despite the fact that the World Health Organization (WHO) and UNICEF in 2009 committed low- and middle-income countries to provide mothers with a home visit of 2 to 3 times in the first week of the postpartum period and give advice regarding infant care (29), this has not been seriously considered in Iran and many other developing countries in South Asia so far. Cheng believes that needs and cares of mothers in the postpartum period have been neglected or not sufficiently considered almost all around the world (30), as such that the scope of this neglect has been drawn to the field of research in the postpartum period (31).

Most studies with educational approach in health centers have been done to raise awareness. Raising awareness through written educational content and oral explanations of staff not only does not lead to maternal efficiency and stress reduction, but also sometimes raises mothers' concerns. Intervention to reduce postpartum stress due to the lack of practical knowledge for self- and newborn care is less studied. Therefore, the present study aims to determine the effect of home-based supportive-educational counseling on postpartum stress of nulliparous women, who have referred to health centers of Zahedan city to show whether home-based supportive-educational counseling interventions can lead to postpartum stress reduction or not?

\section{Materials and Methods}

The present study is a quasi-experimental study with pretest and posttest design. The study has been conducted on 100 primigravidas, who had routinely referred to health centers from May to June 2016 for postpartum care on the third to fifth day after delivery. Qualified women were selected and randomly assigned into two intervention $(n=50)$ and control $(n=50)$ groups. The most important inclusion criteria of the study were being illiterate, singleton pregnancy, a full 37-42 weeks of pregnancy, lack of a history of known mental illnesses, substance abuse, lack of readmission of mother and baby after delivery, vaginal delivery, normal and healthy baby, living with husband, not participating in other educational programs at the same time, and lack of mother's serious health problems that make it difficult for the mother to take care of the baby. The sample size of each group was determined based on the mean and standard deviation of postpartum stress score in similar studies, with a confidence level of $95 \%$, a power function of statistical test of $95 \%$ and based on sample size formula.

Data collection tools in this study were a questionnaire consisting of two parts. The first part was related to demographic questions and information related to delivery stress and the second part was Hung Postpartum Stress Scale (HPSS). HPSS has 61 items and was first designed and developed in 2001 by Hung (10). The questionnaire measures triple stresses related to Maternal Responsibilities and Tasks, Negative Body Changes, and Lack of Social Support. The items are scored based on a 5-point Likert scale as "never" scores 1 and "always" scores 5 . Women determined the amount of stress that each item created in the postpartum period. Postpartum stress score was obtained by summing up the responses to the questionnaire as a whole and the possible score range would be between 62 and 305. A higher score indicated more stress. In Iran, validity of the Persian version of this questionnaire has been proved by Rajabi and Naderi through factor analysis, convergent validity has been proved through Beck Depression Inventory and divergent validity has been proved through Rosenberg Self-Esteem Scale (6). Cronbach a coefficient for the whole questionnaire in this study was 0.91 .

First, qualified women were selected from among nulliparous women referring to health centers for getting postpartum care and samples of children's feet on the third to fifth day after vaginal delivery and their written informed consent to participate in the experiment was received. The 
selected people were randomly assigned to 2 intervention and control groups. The total number of subjects were randomly given envelopes containing group type (A was control group and B was intervention group). Both groups took pre-test by completing the questionnaire.

In the intervention group, the first session was held in the clinic for 30 to 45 minutes by focusing on more essential and important care issues and date and time of the second session was determined by obtaining address and contact number of subjects. Coordination for the third session was determined in the second session based on the condition of the patient. It should be noted that homebased meetings were held in the presence of husbands. Mothers were also given a phone number so as to call the research group in the face of any questions or problems rising during the implementation of the intervention. The control group also received the usual postpartum care given routinely and in accordance with Iran's protocols in two sessions at days 10 to 15 and 42 to 45 after delivery by staff at health centers, which was focused more on controlling and monitoring child development and was not delivered based on specific and planned programs. Mothers' address was obtained for coordination for the post-test.

By the end of the sixth week after delivery, mothers in the intervention and control groups took the post-test when referring to the health centers based on prior coordination. If mothers did not refer to the health center, they took the post-test through in-person visit to their home. Educational content was designed based on resources and studies conducted on individual maternal and neonatal postpartum care, the opinions of experts, the assessment done in Iran and with an emphasis on Hung three postpartum stressors. Physical and psychological self-care, training child care and social support were the bases of interventions that were completed with the help of educational CDs and postpartum support film. Educational and supportive intervention in this study was provided by top experts in obstetrics consultation with 10 years of experience in midwifery.

After collecting data and encrypting using SPSS 20 software, data were analyzed. First, frequency, percentage, mean, standard deviation (SD), minimum, and maximum were determined using descriptive statistics. Then, paired-sample $t$ test was used to compare the mean scores of the 2 groups before and after the intervention; independent $t$ test was used to compare the mean sores of the 2 groups; chi-square was used to compare the frequency of qualitative variables of the 2 groups; and covariance test was used to determine the effectiveness of home-based educational-supportive counseling with simultaneous control of confounding variables. The significance level was considered 0.05 in this study.

\section{Results}

As Table 1 shows the demographic characteristics, the mean age in the intervention and control groups was $22.82 \pm 4.56$ years and $21.02 \pm 5.20$ years, respectively. Independent $t$ test showed no significant difference be-
Table 1. Demographic Characteristics of Intervention and Control Groups

\begin{tabular}{|c|c|c|c|}
\hline Variable & $\begin{array}{l}\text { Intervention } \\
\text { No. (\%) }\end{array}$ & $\begin{array}{l}\text { Control } \\
\text { No. (\%) }\end{array}$ & $\mathbf{P}$ \\
\hline Sex of infant & & & 0.5 \\
\hline Male & $27(54)$ & $23(46)$ & \\
\hline Female & $23(46)$ & $27(54)$ & \\
\hline Total & $50(100)$ & $50(100)$ & \\
\hline Education & & & 0.99 \\
\hline Diploma and lower than & $37(76)$ & $37(76)$ & \\
\hline Higher education & $13(26)$ & $13(26)$ & \\
\hline Total & $50(100)$ & $50(100)$ & \\
\hline Insurance & & & 0.91 \\
\hline Yes & $46(92)$ & $45(90)$ & \\
\hline No & $4(8)$ & $5(10)$ & \\
\hline Total & $50(100)$ & $50(100)$ & \\
\hline Occupation & & & 0.9 \\
\hline Employee & $44(88)$ & $43(86)$ & \\
\hline Unemployed & $6(12)$ & $7(14)$ & \\
\hline Total & $50(100)$ & $50(100)$ & \\
\hline Pregnancy & & & 0.20 \\
\hline Wanted & $48(96)$ & $44(88)$ & \\
\hline Unwanted & $2(4)$ & $6(12)$ & \\
\hline Total & $50(100)$ & $50(100)$ & \\
\hline Abortion history & & & 0.27 \\
\hline Yes & $12(24)$ & $8(16)$ & \\
\hline No & $38(76)$ & $42(84)$ & \\
\hline Total & $50(100)$ & $50(100)$ & \\
\hline Age (mean $\pm S D$ ) & $22.82 \pm 4.56$ & $21.02 \pm 5.20$ & 0.06 \\
\hline
\end{tabular}

tween the 2 groups in terms of mean age $(P=0.06)$. As can be seen, $88 \%$ of the intervention group and $86 \%$ of the control group were employed $(P=0.9)$. Gender composition of babies was $54 \%$ male in the intervention group and $54 \%$ female in the control group $(P=0.5)$. There was compatibility between neonate's gender and desired gender in $82 \%$ of the intervention group and $86 \%$ of control group $(P=0.53)$. Regarding educational level, majority of both groups $(74 \%)$ had a diploma or lower degree and $26 \%$ had higher education degrees $(P=0.99)$. The majority of the intervention group (92\%) and control group (90\%) had insurance services $(P=0.91)$. Also, $96 \%$ of the intervention group and $88 \%$ of the control group had a wanted pregnancy $(P=0.20)$. Moreover, $76 \%$ of intervention group and $84 \%$ of the control group had no history of abortion $(P=0.27)$. There were no significant differences in demographic characteristics between 2 groups.

According to Table 2, findings show that the mean score of postpartum stress reduction in terms of 3 dimensions of negative body changes, maternal role attainment and lack of social support in the intervention group receiving home-based supportive educational counseling was significantly lower than control group $(P=0.0001)$. The mean total score of postpartum stress reduction in the intervention group receiving home-based supportive ed- 
Table 2. Postpartum Stress Scores in Intervention and Control Groups Before and After the Home Visit

\begin{tabular}{|c|c|c|c|c|}
\hline Variable & $\begin{array}{c}\text { Before } \\
\text { Mean } \pm \text { SD }\end{array}$ & $\begin{array}{c}\text { After } \\
\text { Mean } \pm \text { SD }\end{array}$ & $\begin{array}{c}\text { Changes } \\
\text { Mean } \pm \text { SD }\end{array}$ & Paired $T$ Test (Before-After) \\
\hline \multicolumn{5}{|c|}{ Negative body changes } \\
\hline Intervention & $48.08 \pm 6.55$ & $25.32 \pm 6.70$ & $-22.76 \pm 6.05$ & 0.0001 \\
\hline Control & $42.52 \pm 7.25$ & $39.82 \pm 6.32$ & $-2.70 \pm 4.19$ & 0.0001 \\
\hline Independent $\mathrm{t}$ test & 0.001 & 0.0001 & 0.0001 & \\
\hline \multicolumn{5}{|c|}{ Maternal responsibilities and tasks } \\
\hline Intervention & $113.64 \pm 15.64$ & $55.76 \pm 13.11$ & $-57.88 \pm 12.64$ & 0.0001 \\
\hline Control & $110.14 \pm 12.81$ & $90.68 \pm 11.14$ & $-19.20 \pm 8.96$ & 0.0001 \\
\hline Independent t test & 0.2 & 0.0001 & 0.0001 & \\
\hline \multicolumn{5}{|l|}{ Lack of social support } \\
\hline Intervention & $56.96 \pm 9.17$ & $31.28 \pm 4.76$ & $-25.68 \pm 7.33$ & 0.0001 \\
\hline Control & $49.80 \pm 10.47$ & $45.84 \pm 7.76$ & $-3.96 \pm 4.83$ & 0.0001 \\
\hline Independent t test & 0.001 & 0.0001 & 0.0001 & \\
\hline \multicolumn{5}{|c|}{ Total postpartum stress } \\
\hline Intervention & $218.68 \pm 28.57$ & $112.36 \pm 23.36$ & $-106.32 \pm 23.36$ & 0.0001 \\
\hline Control & $202.60 \pm 25.06$ & $176.34 \pm 20.66$ & $-25.87 \pm 15.50$ & 0.0001 \\
\hline Independent t test & 0.004 & 0.0001 & 0.0001 & \\
\hline
\end{tabular}

ucational counseling $(-106.32 \pm 23.36)$ was significantly higher than control group $(-25.87 \pm 15.50)$. By controlling the confounding effect of pre-test, analysis of covariance (ANCOVA) showed that in the post-test the mean total score of postpartum stress in the intervention group was lower than the control group, which showed the positive impact of home-based supportive-educational intervention in this study $(P=0.0001)$.

\section{Discussion}

The present study aimed to determine the effect of homebased supportive-educational counseling on primigravidas' postpartum stress and results showed that postpartum stress, in general, and stresses of the 3 subscale of negative body changes, maternal role attainment and lack of social support after implementing home-based supportive educational counseling in the intervention group was significantly lower than control group. However, results also showed that postpartum stress has been reduced in the control group, although no intervention has been implemented. It seems that infant care in the postpartum period and maternal experiences can lead to mother's self-efficiency and reduction of stresses related to maternal role over time. The finding regarding the control group is in line with the study of Salonen et al (32).

To the best of researcher' knowledge, few studies have investigated the effectiveness of interventions in reducing postpartum stress. This study is the only interventional study that investigates postpartum stress with the help of specialized tools and based on stresses associated with child care, concerns related to physical health problems of women, and social support. The result of meta-analysis performed by Song et al suggest that other intervention studies have primarily measured stress in general and with the help of Perceived Stress Scale (PSS) and parental stress scale $(9,33)$.

The result of the study confirmed Hung's view that if mother's training in the postpartum period is provided with a focus on reducing concerns of neonatal care at birth, methods to increase social and emotional support from their spouses and relatives, and awareness about physical changes and physical appearance and self-care, postpartum stress is reduced $(5,15)$. This study provided a comprehensive and targeted intervention to reduce and cope with the stresses of caring for children and mothers' concerns through raising awareness, responding to the concerns of mothers, teaching newborn caring skills, and supportive interviews. However, in other studies, single interventions such as listening to music (34), physical activity (35), group support meetings (36), biofeedback intervention (4), playing videos and phone calls are provided (9). As Osman et al concluded, when a combination of several means and tools is used for training and consulting, the effectiveness of intervention is increased and this could be one of the reasons that the supportive-educational intervention of this study is effective. In the study of Osman, when a combination of playing postpartum supportive film and 24-hour accountability phone call was presented to a group, the effectiveness of intervention was more than other groups receiving just one of them (9). However, the combination of educational methods and content in the form of a training package and giving it to mothers and husbands is not so hard.

The presence of non-interference, non-supportive, shortterm and one-dimensional interventions in the postpartum period does not have an important role in reducing women's stress. Okamoto et al in Japan showed that one session intervention in the form of a lecture and group discussion, although had contributed to a sense of self-efficacy of some women, but did not have a large impact on 
reducing emotional distress of nulliparous women (17). The study of Salonen et al showed that parental self-efficacy is not only increased in the intervention group, but also it is increased in the control group, which is due to maternal experiencing; also internet child care intervention did not have any effect on parental self-efficacy and mothers' satisfaction (32). It seems that providing not-inperson, non-supportive, and short information does not have significant impact. Maybe the supportive dimension of the present intervention provided in the form of going to women's living area, providing postpartum video, training newborn care (diapers, bathing, feeding, etc), providing 24-hour contact for experienced midwife, which has been less noted in other studies, has helped to reduce stress. The results of the meta-analysis performed by Song et al showed that psychosocial interventions in general and support programs, specifically, are effective for women to cope with postpartum stress (33).

Another important point that has increased the effectiveness of intervention is probably implementation of intervention at home and in the presence of the spouse. Given that official training before and after delivery in Iran is not done in the presence of husbands, the presence of men in home meetings while increasing perceived social protection by women, may increase participation of men in child care in an emergency and thus reduce the stress of women. Perhaps this is the reason that the mean score of postpartum stress associated with lack of social support had significantly decreased in this study. Some other studies including Dritsa et al as home-based physical exercise (35) and study of Roman et al, as alleviating perinatal depressive symptoms and stress, have used home-based intervention to reduce perceived postpartum stress (37), both of which have been effective in reducing perceived stress of women. Some other studies such as the study of Osman et al (9), Tseng et al (34) and Chen et al (36) have used out of home interventions to reduce postpartum stress and some of them including the study of Osman and Tseng have been effective in reducing postpartum stress. Homebased postpartum services are preferred since mothers have some restrictions such as fatigue, pain and physical problems, the problem of transportation and distances, and lack of possibility of leaving the child alone. Studies of Christie and Bunting (38) and also Mirmolaei et al (26) in Iran have shown that satisfaction with the available homebased services is more than other services, which helps to reduce additional stress.

Some studies have evaluated the impact of postpartum stress reduction interventions on vulnerable and problematic groups such as depressed women and low socio-economic classes, which have often been effective because of the nature of the groups $(35,36)$. However, the present study has been conducted on general population of women and, like Osman, showed that home-based educational-supportive intervention affects women in the general population. This shows that this intervention can be applied in larger groups of women in the postpartum period. Nevertheless, the study of Tseng et al (34) that was done on the general population of women showed no significant effect on reducing postpartum stress. Designing interventions that can help larger groups, not just specific and small groups, in reducing postpartum stress is so important, which is considered as strength of this study.

This study had several limitations that should be considered when drawing conclusions. Since intervention was hybrid and multi-dimensional (phone call, video presentations, consulting with husbands, newborn care training), it is unclear exactly which part of the intervention was more or less effective. The stress is different from day to day and its measurement at a time in the pre-test and post-test may be associated with bias. Whether the effect of intervention on reducing postpartum stress is continued after 6 weeks or not has not been investigated in this study.

\section{Conclusion}

Given the global trend of early discharge from hospital after delivery, home-based postpartum care is a very important component of maternity care. Not only it should be child-based, but should be mother-centered, too. There is a huge gap between the vision of maternal postpartum care and the availability and efficacy of this care in many parts of the world, including Iran. Therefore, it is important that relevant departments design and implement appropriate and effective interventions. Given the positive effect of home-based supportive-educational intervention on postpartum stress, specifically stresses related to maternal role attainment, negative body changes, and lack of social support, these supportive-educational multidimensional interventions should be the principle component of maternal and midwifery health programs women in the general population so as to increase the health of the mother and baby care help promote, while reducing mother's stress. Designing and implementing multi-dimensional interventions can replace the process of usual and non-coherent trainings during pregnancy and after delivery. Preparing special guidelines for visiting at home and providing educational content based on mothers' needs are requirements of providing home-based care, and that health care providers should pay sufficient attention in the provision of care. It is necessary in future studies to investigate the effectiveness of these interventions specifically on different groups of women (by cesarean, low birth weight and premature, multiparous women, traumatic childbirth).

\section{Ethical Issues}

The present study is registered in Ethics Committee of $\mathrm{Za}$ hedan University of Medical Sciences under the ethical code of 1395.66.IR.ZAUMS.REC and IRCT2016092529965N1 (http://en.search.irct.ir/view/32914). Providing information on the study, duration of study and intervention, getting written informed consent, ensuring the confidentiality of information, the openness of participating or not participating in any stage of the study were ethical considerations of the study. 


\section{Conflict of Interests}

The authors declare that they have no competing interests.

\section{Financial Support}

The researchers received no financial support or grant from any funding agency in the public and commercial sectors.

\section{Acknowledgments}

The authors thank and appreciate all the women who participated in the study as well as the health care workers of the health care centers of Zahedan University of Medical Sciences. We also thank the Deputy director of Research and Technology of Zahedan University of Medical Sciences.

\section{References}

1. Bener A, Gerber, Sheikh J. Prevalence of psychiatric disorders and associated risk factors in women during their postpartum period: a major public health problem and global comparison. Int J Wom Health. 2012;4:191-200. doi:10.2147/IJWH.S29380.

2. Bahadoran $\mathrm{P}$, Mohseni M, Abedi H. Mothers experiences of postpartum period: a phenomenological study. Iranian J Nursing Midwifery Res 2008;13(3):110-115.

3. Navidian A, Navabi Rigi S, Imani M, Soltani P. The effect of sex education on the marital relationship quality of pregnant women. J Hayat. 2016;22(2):115-127.

4. Kudo N, Shinohara H, Kodama H. Heart rate variability biofeedback intervention for reduction of psychological stress during the early postpartum period. Appl Psychophysiol Biofeedback. 2014;39(3-4):203-211. doi:10.1007/s10484-014-9259-4.

5. Hung $\mathrm{CH}$. Postpartum stress as a predictor of women's minor psychiatric morbidity. Community Ment Health J. 2007;43(1):1-2. doi:10.1007/s10597-006-9066-3.

6. Rajabi G, Naderi Z. Psychometric properties for the Persian version of the postpartum stress scale. Iranian J Psychiatry Clin Psychol. 2013;19(1):65-72.

7. Glavin K, Leahy-Warren P. Postnatal depression is a public health nursing issue: perspectives from Norway and Ireland. Nurs Res Pract. 2013;2013:813409. doi:10.1155/2013/813409.

8. Webb DA, Bloch JR, Coyne JC, Chung EK, Bennett IM, Culhane JF. Postpartum physical symptoms in new mothers: their relationship to functional limitations and emotional well-being. Birth. 2008;35(3):179-187. doi:10.1111/j.1523536X.2008.00238.x.

9. Osman H, Saliba M, Chaaya M, Naasan G. Interventions to reduce postpartum stress in first-time mothers: a randomized-controlled trial. BMC Womens Health. 2014;14:125. doi:10.1186/1472-6874-14-125.

10. Hung $\mathrm{CH}$. The construct of postpartum stress: A concept analysis. J Nur. 2001;48:69-76.

11. Nazari S, Salari P, Mazlom R, Mahram B. Comparison of social support in the first and second month of postpartum in multiparous. Community Health J 2014;8(2):1-9.

12. Navidian A, Rigi SN, Soltani P. Effects of group sexual counseling on the traditional perceptions and attitudes of Iranian pregnant women. Int J Womens Health. 2016;8:203211.

13. Navidian A, Kermansaravi F, Navabirigi SH, Saber S,
Saeedinegad F. Correlation between postpartum stress and social support in nulliparous women. J Health Promotion Manag. 2015;5(1):40-49.

14. Salehi H, Simbor M, Abolghasemi A, Abdi A. Comparison of postpartum depression in women with both emotionfocused coping strategies and problem-focused in low risk pregnancies. J Qom Univ Med Sci. 2013;2(7):35-40.

15. Hung CH, Lin CJ, Stocker J, Yu CY. Predictors of postpartum stress. J Clin Nurs. 2011;20(5-6):666-674. doi:10.1111/ j.1365-2702.2010.03555.x.

16. Beck CT, Gable RK, Sakala C, Declercq ER. Posttraumatic stress disorder in new mothers: results from a two-stage U.S. National Survey. Birth. 2011;38(3):216-227. doi:10.1111/ j.1523-536X.2011.00475.x.

17. Okamoto M, Ishigami H, Tokimoto K, Matsuoka M, Tango R. Early parenting program as intervention strategy for emotional distress in first-time mothers: a propensity score analysis. Matern Child Health J. 2013;17(6):1059-1070. doi:10.1007/s10995-012-1088-6.

18. Mohseni M, Loripoor M, Nekuei N. Educational needs of postpartum period in women referring to health care centers of Rafsanjan in 2008. Comm Health J. 2013;7(1):1827.

19. Hung Ch. Measuring postpartum stress. J Adv Nursing 2005;50(4):417-424. doi:10.1111/j.1365-2648.2005.03407.x.

20. Woolhouse H, Mercuri K, Judd F, Brown SJ. Antenatal mindfulness intervention to reduce depression, anxiety and stress: a pilot randomized controlled trial of the Mind Baby Body program in an Australian tertiary maternity hospital. BMC Preg Childbirth. 2014;14(1):369. doi:10.1186/s12884014-0369-z.

21. Azizzadeh Forouzi M, Mohamadalizadeh S, Soltanahmadi Zh, Ghazanfari Z. Postpartum stressors from mothers point of view. Iranian J Obstet Gynecol Infertil. 2009;12(4):45-52.

22. Perez-Blasco J, Viguer P, Rodrigo MF. Effects of a mindfulness-based intervention on psychological distress, well-being, and maternal self-efficacy in breast-feeding mothers: results of a pilot study. Arch Womens Ment Health. 2014;16:227-236. doi: 10.1007/s00737-013-0337-z.

23. Bloomfield L, Kendall S. Parenting self-efficacy, parenting stress and child behaviour before and after a parenting program. Prim Health Care Res Dev. 2012;13(4):364-372. doi: $10.1017 /$ S1463423612000060.

24. Dennis CL. Psychosocial and psychological interventions for preventing postpartum depression: systematic review. BMJ. 2005;331:15-21. doi:10.1136/bmj.331.7507.15.

25. Azmoude E, Jaafarnejad F, Mazloum S. Effect of selfefficacy-based training on maternal sense of competency of primiparous women in the infants care. Evid Based Care. 2014;4(3):7-14.

26. Mirmolaei ST, Amel Valizadeh M, Mahmoodi M, Tavakol Z. The effect of postpartum home care on maternal practices in infant care. Jurnal of Urmia Nursing Midwifery 2012;10(3):441-448.

27. Gamble J, Creedy DK. A counselling model for postpartum women after distressing birth experiences. Midwifery. 2009;25(2):21-30. doi:10.1016/j.midw.2007.04.004.

28. Delaram M, Raeisi Dehkordi SA. The effect of counseling with nulliparous women during third trimester on pregnancy outcomes. Jundishapur Sci Med J. 2012;11(4):355-363.

29. Hanson C, Manzi F, Mkumbo E, et al. Effectiveness of a home-based counselling strategy on neonatal care and survival: a cluster-randomised Trial in six districts of 
rural southern Tanzania. PLoS Med. 2015;12(9):e1001881. doi:10.1371/journal.pmed.1001881.

30. Cheng CY, Li Q. Integrative review of research on general health status and prevalence of common physical health conditions of women after childbirth. Womens Health Issues. 2008;18(4):267-280. doi:10.1016/j.whi.2008.02.004.

31. Cheng CY, Fowlers ER, Walker LO. Postpartum maternal care in the United State: A critical review. J Perinat Educ. 2006;15(3):34-42. doi:10.1624/105812406X119002.

32. Salonen AH, Kaunonen M, Astedt-Kurki P, Jarvenpaa AL, Isoaho H, Tarkka MT. Effectiveness of an internetbased intervention enhancing Finnish parents' parenting satisfaction and parenting self-efficacy during the postpartum period. Midwifery. 2011;27:832-841. doi:10.1016/j.midw.2010.08.010.

33. Song JE, Kim T, Ahn JA. A systematic review of psychosocial interventions for women with postpartum stress. J Obstet Gynecol Neonatal Nurs. 2015;44(2):183192. doi:10.1111/1552-6909.12541.

34. Tseng YF, Chen CH, Lee CS. Effects of listening to music on postpartum stress and anxiety levels. J Clin Nurs. 2010;19(78):1049-1055. doi:10.1111/j.1365-2702.2009.02998.x.

35. Dritsa M, Dupuis G, Lowensteyn I, Da Costa D. Effects of home-based exercise on fatigue in postpartum depressed women: who is more likely to benefit and why? J Psychosom Res. 2009;67(2):159-163. doi:10.1016/j. jpsychores.2009.01.010.

36. Chen CH, Tseng YF, Chou FH, Wang SY. Effects of support group intervention in post natally distressed women. A controlled study in Taiwan. J Psychosom Res. 2000; 49(6):395-399. doi.org/10.1016/S0022-3999(00)00180-X.

37. Roman LA, Gardiner JC, Lindsay JK, et al. Alleviating perinatal depressive symptoms and stress: a nursecommunity health worker randomized trial. Arch Womens Ment Health. 2009;12(6):379-391. doi:10.1007/s00737-0090083-4.

38. Christie J, Bunting B. The effect of health visitors' postpartum home visit frequency on first-time mothers: Cluster randomised trial. Int J Nurs Stud. 2011;48(6):689702. doi:10.1016/j.ijnurstu.2010.10.011.

Copyright ( 2017 The Author (s); This is an open-access article distributed under the terms of the Creative Commons Attribution License (http://creativecommons.org/licenses/by/4.0), which permits unrestricted use, distribution, and reproduction in any medium, provided the original work is properly cited. 